\title{
Information system for environmental monitoring using adaptive semantic models
}

\author{
Tamara Shikhnabieva ${ }^{1, *}$, and Nurjagan Bulaeva ${ }^{2}$ \\ ${ }^{1}$ Plekhanov Russian University of Economics, Stremyanny per. 36, 117997 Moscow \\ ${ }^{2}$ LLC Center of the Conjugated Monitoring of Environment and Natural Resources, Selivantyeva St. \\ 2, 367027 Makhachkala, Dagestan republic
}

\begin{abstract}
Effective environmental monitoring requires intelligent information systems. Developing such systems is associated with numerous challenges concerning the presentation, processing, and use of geochemical and environmental. The paper proposes several approaches to solving these problems, implemented using adaptive semantic models.
\end{abstract}

\section{Introduction}

An essential factor influencing the living standard of the population is the quality of the environment, i.e. water, air, and soil. Currently, the anthropogenic factor, along with the natural risk factors, has a great impact on the ecological balance. Therefore, environmental monitoring is necessary, which should have a socio-economic focus since environmentrelated information should determine social policy and changes in the economy aimed at improving the quality of life. Environmental monitoring is important for increasing environmental awareness among the population, public officers, managers and employees of various enterprises, which, in turn, helps to create a conscious and careful attitude towards nature, as well as towards environmental studies.

When assessing the condition of various environments, researchers should compare the biological, physical, and chemical properties of water, air, or soil with the accepted standards to reveal possible deviations. Environmental information provided by physical investigation and biogeochemical analysis can be processed and visualized not only in tabular but also in cartographic forms. When mapping certain changes in environmental parameters, it is necessary to quickly process and analyze large amounts of information to make better solutions. The paper discusses the issue of using information systems based on adaptive semantic models for solving these tasks.

\section{Functions of the developed information system}

The authors have developed an information system based on techniques of unbiased, information-bearing, and visual display of the man-nature interaction and its results. The tasks of the proposed system include the generalization of environmental data that can be

\footnotetext{
*Corresponding author: shetoma@mail.ru
} 
of interest to consumers, providing territorial references, and presenting information in the form convenient for comparison and analysis. The system allows obtaining maps of various environmental parameters showing the structure and degree of environmental issues in certain territories, revealing the causes of pollution and possible consequences, and providing recommendations for improving the situation.

For mathematical models of different complexity degrees, different numbers of input parameters can be used. Advanced intelligent systems on the basis of adaptive semantic models [1] make it possible to automatically transform and generalize the original data presented on the map and ensure high spatiotemporal resolution of results. Using intelligent methods and models, including adaptive semantic models, for environmental monitoring, as well as for impact assessment of natural and anthropogenic factors, is a promising trend in the development of environmental information systems. Such systems facilitate the presentation and perception of data, allow analyzing, processing, forecasting, and modeling different situations for identifying the optimal balance between the environment and society necessary for their coexistence, based on the principle of sustainable development. Hierarchical adaptive semantic models make it possible to develop a comprehensive system of environmental information. The components of such a system are a powerful operating system, a convenient user interface, and an algorithm for creating databases and displaying information. Developing an integrated system for environmental monitoring is a relevant task for solving numerous environmental, geographical, and geological problems. Information systems based on adaptive semantic models have characteristics of expert systems; they contain databases and knowledge bases that make it possible to analyze and revise data regardless of users' privileges, make relevant decisions on the user's request or regardless of such a request, and solve numerous tasks related to the classification and analysis of data.

\section{Examples of using the developed information system}

LLC Center of the Conjugated Monitoring of Environment and Natural Resources (Makhachkala, the Republic of Dagestan) implements a scientific program aimed at studying the possible functions and use areas of advanced GIS technologies and intelligent models related to environmental monitoring and developing environmental information systems based on such technologies. In particular, the research team of the Center has developed a special GIS package for monitoring the Republic of Dagestan territory. Since environmental mapping relies on the concept of biogeochemical sources of pollutant migration in the natural environment, the development of a geoinformation system aimed at solving this task required building models based on the approaches and principles of different sciences, including meteorology, hydrology, landscape geometry, cybernetics, landscapes, etc.

The most essential factor influencing the distribution of pollutants in the environment is the terrain, as well as the "means" of transportation of pollutants - the atmosphere, lithosphere, and hydrosphere. As a basis for further environmental study, the researchers used the developed information system to build a model of the terrain of Makhachkala based on heterogeneous environmental parameters. 


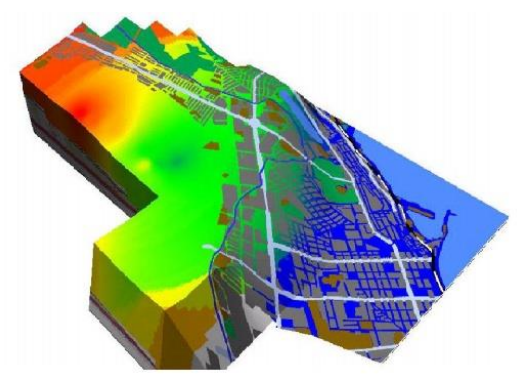

Fig 1. Electronic 3.D model of t.he topograp.hy of the c.ity of Mak.hachkala.

When studying the environmental parameters of territories, researchers compile thematic maps as models of real natural objects. Such maps provide a visual layer-bylayer image of the terrain. The basic information contained in these maps includes the data of relief and hydrography [2, 4, 5, 12, 14]. Information control at all stages is implemented manually and requires a team of qualified experts. Information systems using adaptive semantic models make it possible to significantly accelerate mapping processes. Besides, it is currently possible to represent conventional two-dimensional maps as $3 \mathrm{D}$ models, that is, in the Cartesian coordinate system, in which people perceive the surrounding world.

The main task of intelligent information systems is to contribute to solving environmental issues and preventing the emergence of new ones. Such systems can be used by environmental experts or environmental research organizations as reference guides for making specific decisions aimed at improving the quality of the environment $[3,5,6,7,8,12,15]$. Intelligent information systems can be widely applied for the ecological monitoring of the city territory $[11,13]$.

The current paper identifies the stages of modeling an information system of environmental monitoring for the territory of the Republic of Dagestan (Fig. 2). The basis for the work was the topographic map of Dagestan $(1: 500,000)$ in a digital format. The research team carried out digitization (vectorization) of the raster image of the topographic map and identified specific layers with corresponding attributes and table database: horizontal, water bodies, river system, and boundaries. The advantage of the obtained map is the possibility to work with it interactively: it is possible to make changes or display only the information of interest from the database for the ease of reading and using and for minimizing the load.

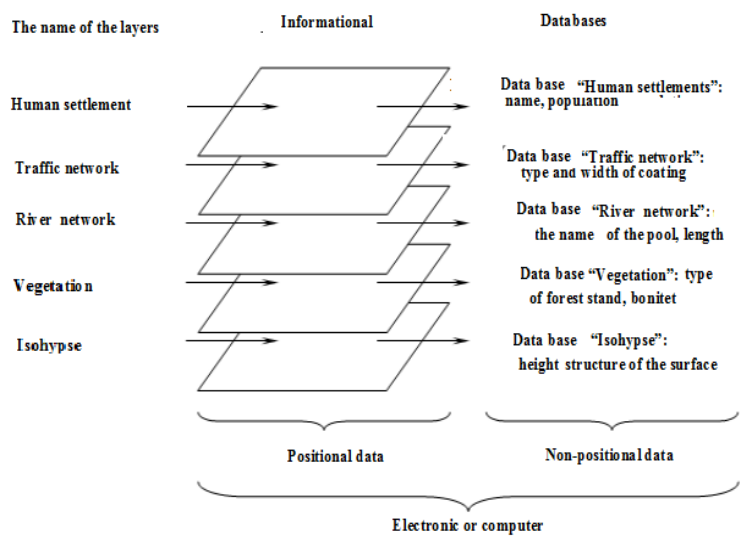

Fig. 2. Information modeling sc.heme of the reg.ion. 
One of the essential components of the natural environment is relief, which influences the redistribution of atmospheric moisture and temperature, as well as surface wind conditions, and so contributes to shaping a specific microclimate, having an indirect impact on soil and vegetation. Relief determines all the parameters of the terrain: the structure of the hydrographic network, distribution of soil cover and vegetation, location of roads and settlements, microclimate, and environmental conditions. The terrain is crucial for economic development and construction in the territory. Figs. 3 and 4 present the results of modeling the pollution in the city of Makhachkala obtained using the developed system.

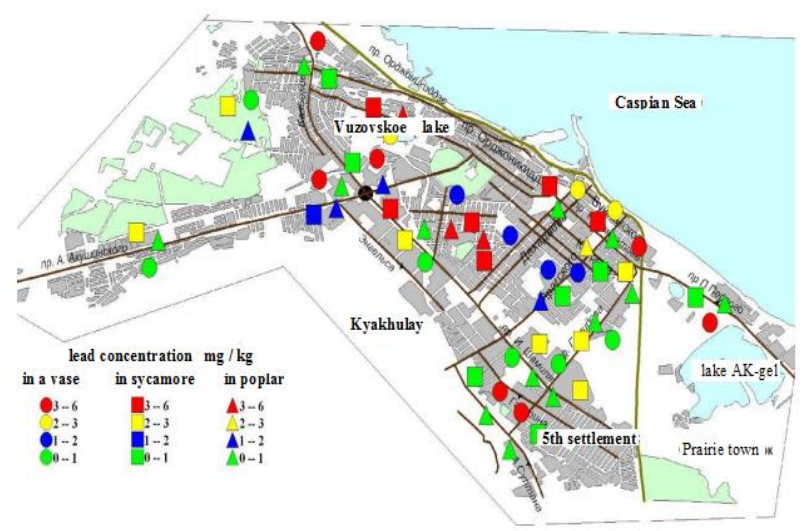

Fig. 3. Lead conte.nt in the p.hytomass o.f different t.ree species i.n the city o.f Makhachk.ala.

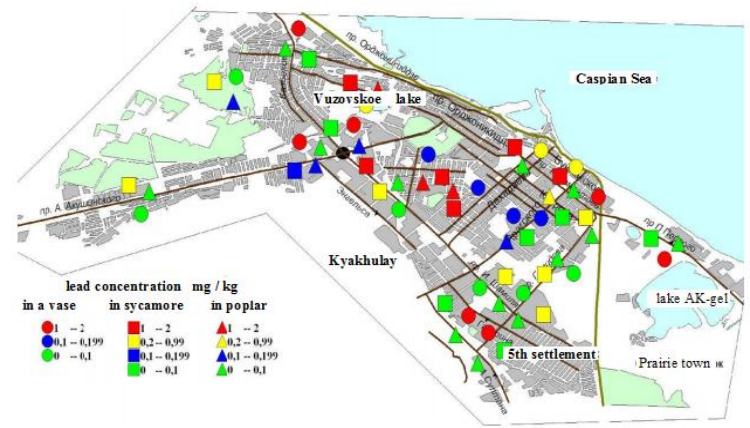

Fig. 4. Cadmium co.ntent in t.he phytomass o.f various t.ree species i.n Makhachk.ala.

\section{Conclusion}

The results obtained by the authors show the prospects of applying information systems based on adaptive semantic models and long-term observations as an environmental monitoring tool. In terms of environmental state, Makhachkala is one of moderately polluted cities of the Russian Federation. The natural environment of the city is gradually changing due to human economic activity. Technogenic pollution influences all landscape components, but first of all the depositional environment is affected: atmospheric air, soil, and biota. A study of possibilities and prospects of applying intelligent information systems based on adaptive semantic models for environmental monitoring contributes to identifying the response of the environment to anthropogenic changes. The advantage of the system proposed by the authors is that the position of the analyzed points in space 
does not change, only the information about objects that can be stored and processed in the system, taking into account the goals of environmental research.

\section{Further research}

Taking into consideration the above theses, it is possible to formulate a further purpose of the work, which is to map the localities of the Republic of Dagestan in order to evaluate the settlement density in various geomorphological zones, determine territories with the greatest human-induced load on the environment, and to analyze the response of the environment to anthropogen ic changes. The authors also plan to map the types of soil that are characteristic of various territories and their ecological state, determine the level of natural radioactive contamination of rivers and river basins, and develop GIS technology using electronic 3D models of water, soil, and air pollution for environmental monitoring of the region.

\section{References}

1. T. Shikhnabieva, S. Beshenkov, Smart Education and e-Learning, 595 (2016) http://link.springer.com

2. N.O. Huseynova, N.M. Bulaeva, B.I. Magomedov, S.Y. Askerov, IX International Conference "Biodiversity of Caucasus": Materials of the Conference, 16 (2007)

3. G.M. Abdurakhmanov, M.I. Karpyuk, B.N. Morozov, Yu.G. Puzachenko, Current State and Factors Determining Biological and Landscape Diversity of the VolgaCaspian Region of Russia (2002)

4. A.M. Berlyant, Virtual Mapping (1999)

5. V.E. Gershenzon, E.V. Smirnova, E.O. Elias, Information Technologies in Environmental Protection (2003)

6. K. Gul, S. Vlasova, Geography of Dagestan (1960)

7. A.M. Zhukov, Computer Geoenvironmental Modeling (1998)

8. V.S. Tikunov, Basics of Geoinformatics, 1-2 (2004)

9. T.A. Trifonova, N.V. Mischenko, A.N. Krasnoschekov, Geographic Information Systems and Remote Sensing in Ecological Research (2005)

10. T.Sh. Shikhnabieva, M.I. Ramazanova, O.K. Akhmedov, Monitoring. Science and Technologies, 2, 72 (2015).

11. N.M. Bulaeva, A.D. Filenko, E.M. Magomedbekov, N.O. Huseynova, Bulletin of the Dagestan Scientific Center, 24, 32 (2006)

12. N.M. Bulaeva, Monitoring. Science and technologies, 4(25), 45 (2015)

13. T.Sh. Shikhnabieva, Monitoring. Science and Technologies, 3(32), 74 (2017)

14. N.M. Bulayeva, Y.V. Kaplunov, A.Y. Globa, Monitoring. Science and Technologies, 2, 71 (2014)

15. M. Favorskaya, L.C. Jain, A. Proskurin, New Approaches in Intelligent Image Analysis: Techniques, Methodologies and Applications, 123 (2016) 